\title{
Sexual Dysfunction in Breast Cancer Survivors: \\ Cross-Cultural Adaptation of the Sexual Activity \\ Questionnaire for Use in Portugal
}

\section{Disfunção Sexual em Sobreviventes de Cancro da Mama: Adaptação Cultural do Sexual Activity Questionnaire para Uso em Portugal}

\author{
Filipa Alves da COSTA $\triangle^{1,2}$, Manuel Castro RIBEIRO ${ }^{1,3}$, Sofia BRAGA ${ }^{4}$, Elisabete CARVALHO ${ }^{5}$, Fátima FRANCISCO ${ }^{5}$, \\ Ana da Costa MIRANDA ${ }^{1}$, António MOREIRA ${ }^{4,5}$, Lesley FALLOWFIELD ${ }^{6}$
}

Acta Med Port 2016 Sep;29(9):533-541 - http://dx.doi.org/10.20344/amp.7389

\section{ABSTRACT}

Introduction: The increasing survivor population of breast cancer has shifted research and practice interests into the impacts of the disease and treatment in quality of life aspects. The lack of tools available in Portuguese to objectively evaluate sexual function led to the development of this study, which aimed to cross-culturally adapt and validate the Sexual Activity Questionnaire for use in Portugal. Material and Methods: The questionnaire was translated and back-translated, refined following face-to-face interviews with seven breast cancer survivors, and then self-administered by a larger sample at baseline and a fortnight later to test validity and reliability. Results: Following cognitive debriefing $(n=7)$, minor changes were made and the Sexual Activity Questionnaire was then tested with 134 breast cancer survivors. A 3-factor structure explained $75.5 \%$ of the variance, comprising the Pleasure, Habit and Discomfort scales, all yielding good internal consistency (Cronbach's $\alpha>0.70$ ). Concurrent validity with the FACt-An and the BCPT checklist was good (Spearman's $r>0.65 ; p$-value $<0.001$ ) and reliability acceptable (Cohen's $k>0.444$ ). The Sexual Activity Questionnaire allowed the identification of $23.9 \%$ of sexually inactive women, for whom the main reasons were lack of interest or motivation and not having a partner.

Discussion: Patient-reported outcomes led to a more comprehensive and improved approach to cancer, tackling areas previously abandoned. Future research should focus on the validation of this scale in samples with different characteristics and even in the overall population to enable generalizability of the findings.

Conclusion: The adapted Sexual Activity Questionnaire is a valid tool for assessing sexual function in breast cancer survivors in Portugal.

Keywords: Breast Neoplasms/psychology; Portugal; Sexual Behavior/psychology; Sexuality/psychology; Surveys and Questionnaires; Validation Studies.

\section{RESUMO}

Introdução: A crescente população de sobreviventes de cancro da mama tem redireccionado o interesse investigacional e prático para o impacto da doença e do seu tratamento nas várias áreas da qualidade de vida. A falta de questionários para avaliar de forma objectiva a disfunção sexual conduziu à necessidade de adaptar e validar culturalmente o Sexual Activity Questionnaire para utilização em Portugal.

Material e Métodos: O Sexual Activity Questionnaire foi traduzido e retrovertido, sua versão de consenso refinada após teste de compreensão, e subsequentemente auto-administrado a uma amostra alargada de sobreviventes de cancro da mama em dois momentos, espaçados 15 dias, para julgar a sua validade e fiabilidade.

Resultados: Após alterações minor à versão de consenso, o Sexual Activity Questionnaire foi aplicado a 134 doentes. Obteve-se uma estrutura de três factores $(75,5 \%$ da variância), compreendendo as escalas do Prazer, Hábito e Desconforto, todas com boa consistência interna ( $\alpha$ de Cronbach $>0,70$ ), boa validade concorrente com o FACt-An e a checklist BCPT ( $r$ de Spearman $>0,65 ; p$-value $<0,001$ ) e estabilidade temporal aceitável ( $k$ de Cohen $>0,44$ ). Foi identificada inactividade sexual em $23,9 \%$ das mulheres, devido a falta de interesse ou ao facto de não ter parceiro.

Discussão: Os dados reportados pelos doentes conduziram a alterações nos cuidados prestados, que passaram a contemplar a oncosexologia. Estudos futuros deverão focar-se na aplicabilidade deste questionário a amostras com diferentes características e mesmo à população global, para se poderem generalizar os resultados.

Conclusão: A versão obtida do Sexual Activity Questionnaire é válida para avaliar a função sexual em sobreviventes de cancro da mama em Portugal.

Palavras-chave: Comportamento Sexual/psicologia; Estudos de Validação; Inquéritos e Questionários; Neoplasmas da Mama/psicologia; Portugal; Sexualidade/psicologia.

\footnotetext{
1. Serviço de Epidemiologia. Instituto Português de Oncologia de Lisboa Francisco Gentil. Lisboa. Portugal.

2. Centro de Investigação Interdisciplinar Egas Moniz. Costa da Caparica. Portugal.

3. Centro de Recursos Naturais e Ambiente. Instituto Superior Técnico. Universidade de Lisboa. Lisboa. Portugal.

4. Serviço de Oncologia Médica. Instituto Português de Oncologia de Lisboa Francisco Gentil. Lisboa. Portugal.

5. Unidade de Investigação Clínica. Instituto Português de Oncologia de Lisboa Francisco Gentil. Lisboa. Portugal.

6. Unit of Psycho Oncology. Sussex Health Outcomes Research \& Education in Cancer (SHORE-C). Brighton \& Sussex Medical School. University of Sussex. Sussex. United Kingdom.

$\triangle$ Autor correspondente: Filipa Alves da Costa. alvesdacosta.f@gmail.com

Recebido: 11 de janeiro de 2016 - Aceite: 26 de agosto de 2016 | Copyright @ Ordem dos Médicos 2016
} 


\section{INTRODUCTION}

Recent World Health Organization data showed that 521,000 deaths of the 8.2 million deaths from cancer in 2012 were due to breast cancer. ${ }^{1}$ In Portugal, breast has the highest incidence rate of all cancers (approximately $30 \%$ of the total of female cancer cases) with figures increasing. ${ }^{2}$ Probably as a result of earlier detection and improved treatment, mortality for breast cancer has been decreasing in most European countries. In Portugal, mortality decreased $2 \%$ between 1992 and $2002,{ }^{3}$ followed by a sharper decline recently. ${ }^{4}$ Breast cancer also has one of the highest survival rates across cancer sites and this too is increasing each year. In Portugal, age-standardized relative survival at one and at five years is $95 \%$ and $83 \%$, respectively, ${ }^{5}$ therefore, there is a growing population of breast cancer survivors. Although the overall quality of life (QoL) of survivors is quite high, ${ }^{6}$ specific aspects of QoL such as fatigue, weakness, insomnia and sexual functioning may be particularly affected in this population. ${ }^{7}$ Sexual and fertility problems are especially prevalent. ${ }^{6}$ In one Australian study of 1,011 breast cancer survivors, $70 \%$ experienced sexual problems in the two years following diagnosis. Over $80 \%$ of these patients claimed to be having a satisfying sex-life prior to diagnosis. Those taking aromatase inhibitors were $50 \%$ more likely to report sexual problems than women treated with tamoxifen or not having any hormonal therapy. Interestingly $77 \%$ women had hot flushes and night sweats which were associated with sexual difficulties. ${ }^{8}$

Female sexual dysfunction is multifactorial, involving physiological, psychological, social and economic components, and may be subdivided into four categories: hypoactive desire, arousal, orgasm and sexual pain. ${ }^{9}$

Some studies suggest that the incidence of sexual dysfunction increases as estrogen levels decrease, ${ }^{10}$ whilst others mention increasing age ${ }^{11}$ aspects seeming inter-related because menopausal symptoms occur with increasing age and can increase as a result of breast cancer therapies. $^{12}$

Breast cancer is in itself a factor for sexual dysfunction, but some treatments can lead to early and intensified menopausal symptoms. ${ }^{13}$ Surgery may also affect body image and self-esteem, ${ }^{14}$ though impact on sexual activity may vary according to surgery performed. ${ }^{15}$

There are scarce data concerning the prevalence of female sexual dysfunction in the general population; the few data available indicate a wide range of values. ${ }^{16}$ Studies often include populations of different ages, with various morbidities, using several scales to measure sexual dysfunction, limiting comparisons. Lewis and colleagues reviewed descriptive epidemiological studies and indicated that one may expect to find some form of manifest sexual dysfunction in $40 \%-45 \%$ of adult women. ${ }^{17}$ However, the prevalence may vary depending on the specific dysfunction studied e.g. sexual desire decreases with age. Certain comorbid conditions may influence sexual dysfunction in females such as diabetes and thyroid diseases, raising around $20 \%$ the prevalence of sexual dysfunction observed in premenopausal women. ${ }^{18,19}$

The prevalence reported among breast cancer survivors ranges between $37 \%$ and $51 \% .^{20}$ Time elapsed since diagnosis seems to have little effect; there are reports showing that the prevalence increases only $2 \%$, when comparing women who finished treatment one year and ten years before. ${ }^{21}$

The first-line treatment for women with breast cancer at the time of study in Portuguese Oncology Institute in Lisbon (IPOLFG) was tamoxifen alone. Recently, following publication of the SOFT trial, other ovarian suppression treatment options have been implemented for premenopausal women with high risk of recurrence. ${ }^{22}$ Also, newly implemented practice guidelines indicate continuation of tamoxifen treatment for 10 years, following results the aTTom ${ }^{23}$ and the ATLAS trials. ${ }^{24}$ These changes in clinical practice are expected to improve direct outcomes from the disease but may also increase the prevalence of sexual dysfunction.

The IPOLFG is a specialized hospital for cancer care, distinguished by its advanced treatment options, the completeness of its registry, its involvement in oncology research and its interest in the development of new absent areas of therapy. With increasing survival for breast cancer, focus has been given to the evaluation of specific areas of QoL of cancer survivors that may need additional care, such as sexual life. The lack of treatment of sexual dysfunction has been reported internationally to be as high as $90 \% .{ }^{25}$ IPOLFG at the time did not offer patients specific help with sexual problems, so wanted to assess the need for developing a sexual-oncology clinic. Consequently a validated tool was required for use in Portugal to measure sexual activity.

At the time of the study two tools were available. The Female Sexual Function Index, a 19-item questionnaire addressing the four clinical entities defined by the DSM-IV, that had been used in a 96 generic patient sample (both genders) indicating $40 \%$ of changes in the female sexual desire. ${ }^{26}$ This questionnaire is currently validated for Portugal, ${ }^{27}$ but at the time this study began only a Brazilian version existed. ${ }^{28}$

The second available questionnaire was the Short Personal Experiences Questionnaire, which had been used in a multicentre study involving 12 countries, including Portugal. ${ }^{29}$ However, the outcome measure was the frequency of sexual activity and not the prevalence of sexual dysfunction, which is a different aspect likely to be influenced by the country of origin.

Additional literature search suggested the Fallowfield's Sexual Activity Questionnaire (SAQ) to be the measurement tool with most advantages and vaster experience in cancer research. This tool evaluates sexual dysfunction in three domains: pleasure, discomfort and habit, with their correlation seeming to vary according to the groups of patients being compared..$^{30}$ Nonetheless, SAQ has been used in various countries, maintaining its original 3-domain 
structure and good psychometric properties. ${ }^{31}$

Our ultimate goal, the thorough identification and quantification of sexual dysfunction among female breast cancer survivors, as a basis for the development of a multidisciplinary approach to treatment covering all affected areas of QoL, required us first to cross-culturally adapt and validate the SAQ in Portuguese.

\section{MATERIAL AND METHODS}

\section{Study design and setting}

An exposure cohort of patients treated at IPOLFG between 2008 and 2010 was constituted and followed during 15 days for validation purposes. The study comprised the translation and back translation, ${ }^{32}$ followed by the evaluation of the psychometric properties of the Portuguese version (Appendix 1, available at: http://www. actamedicaportuguesa.com/revista/index.php/amp/article/ view/7389/7389_Appendix01.pdf).

\section{Population}

The population of interest for validation purposes was women with local breast cancer (stages I to III), diagnosis histologically confirmed $<10$ years before, pre-menopausal or aged $\leq 50$ years at the time of diagnosis, with complete treatment (surgery, chemotherapy, or radiotherapy, except for hormonotherapy) and monitored at IPOLFG, with no clinical manifestations of disease at the time of study (full remission) and being able to read and write. Women with chronic psychiatric disease (treated by a psychiatrist and medicated for at least six months) were excluded.

\section{Sample}

Three samples were constituted for the different stages of questionnaire validation. The first sample for face and content validation of the SAQ, comprised seven women selected at the oncology appointment by two of the medical researchers ( $A M$; $S B$ ), aiming to represent a range of educational levels.

A second sample was randomly extracted from the cancer registry database, and women were then contacted to participate in the study. The estimated sample size was 100 , considering the scale has 20 items and 3 domains, following recommendations. ${ }^{33}$ This sample cross-sectionally tested construct validity, internal consistency, discriminant validity and concurrent validity.

A third sample was also extracted from the cancer registry database, aiming for a minimum of 30 participants, as indicated in previous work, where those having the nearest medical oncology appointment were invited to participate in the study. These answered the SAQ on the day of medical appointment and received a second questionnaire to be answered 15 days after and sent using a reply-paid envelope, to test temporal stability, as a form of reliability. ${ }^{34}$

\section{Recruitment method}

Study participants identified in the cancer registry database, by random extraction, and subsequently clinical records were verified to ensure it was a remission case. For all confirmed cases, the medical doctor was contacted to recruit the patient at the nearest scheduled appointment. On that occasion, the patient was approached by one of the researcher nurses (EC; FF) and informed (orally and in written) about the study goals. Patients declining participation were asked to fill in a refusal form and those accepting to participate signed an informed consent form prior to receiving the questionnaires. Patients received two sets of questionnaires, differentiated by color, one completed on the day of the medical appointment and another answered 15 days later. Patients received replypaid envelopes and reminder phone calls to minimize dropouts.

\section{Questionnaires}

Participants were asked to answer the SAQ and the Breast Cancer Prevention Trial Symptom Checklist (BCPT) in two moments 15-days apart and to answer the Hospital Anxiety and Depression Scale (HADS) and the Functional Assessment Cancer Trial-Anemia (FACT-An) at baseline.

The SAQ is divided into three sections: 1) a screening section where existence of a partner and sexual activity is assessed; 2) evaluation of the reasons for sexual inactivity (when applicable) and; 3) 10 statements to evaluate sexual function, contributing to three domains: pleasure (six items), discomfort (two items) and habit (one item). The pleasure and habit domains are rated in a direct manner, i.e., the higher the score, the more pleasure and habit, as these affect positively sexual function. The discomfort scale is interpreted in a reverse way, where higher scores indicate more discomfort, as this affects negatively sexual function.

The HADS generates two scores, referring to depression and anxiety, where higher values represent higher impairment, i.e., more depressed and/or anxious. ${ }^{35}$ The FACT-An comprises various subscales, evaluating physical, social, emotional and functional well-being, in addition to fatigue (a subscale of anemia), which overall provide a measure of the QoL of women with cancer. The higher the score obtained in the FACT-An, the better the patient's QoL. ${ }^{36}$

\section{Measurement properties and statistics}

Data collected for analysis was first stored in a MS Access 2000 database. Statistical software R 3.1.137 was used for statistical tests and multivariate analysis (Principal Component Analysis - PCA). The validation focused on section three of the SAQ and included assessment of face and content validity, construct validity, internal consistency, discriminant validity, concurrent validity and temporal stability.

Face and content validity were evaluated during cognitive debriefing, consisting of face-to-face interviews with breast cancer women, where participants were requested for each response option, to rate the clarity of terms, their ability to discriminate between different aspects of sexual activity 
(comprehensiveness and redundancy), and the eventual intrusive character of questions asked.

Construct validity was assessed by exploratory factor analysis, using PCA with varimax rotation. The KaiserGuttman criterion was used for selecting the number of factors to retain. Internal consistency of each domain was assessed by Cronbach's alpha.

The Kruskal-Wallis (two groups) or Mann-Whitney U (>2 groups) tests, as appropriate, were used to compare median scores in SAQ's domains to judge discriminant validity. To further explore interpretation and analysis of discriminant and construct validity, projection of supplementary variables on PCA results was used. Projection of hormonal status, anxiety and depression scores (HADS), anemia and fatigue scores (FACT-An) were analysed on the SAQ domains.

Concurrent validity was assessed by forming a priori hypothesis on the correlations between the SAQ and other covariates. The answers to item seven of the BCPT, evaluating pain during intercourse were compared with the scores obtained for the discomfort domain of the SAQ. Using the same rationale, item G57, of the FACT-An evaluating sexual satisfaction (independently of frequency) was compared with scores obtained for the pleasure domain of the SAQ.

Reliability in the form of temporal stability was assessed by comparing responses to the $S A Q$ in two different time moments through Cohen's Kappa, and Person's or Spearman's test, as described. ${ }^{34}$ In all tests, the significance level considered was $\alpha=0.05$.

\section{RESULTS}

\section{Face and content validity}

Seven women participated in the cognitive debriefing phase, with ages ranging from 28 to 49 years, representing a range of educational levels (from 'no degree' to 'university degree') and professional occupations (e.g. administrative staff, economist, seamstress, technical analyst, child care, housewife).

All participants considered the questionnaire relevant and comprehensive. Most changes suggested consisted of adding extra response options in section II, pertaining to reasons for sexual inactivity (e.g. not feeling motivated; not feeling sexy; my partner rejects my body). One participant considered that in the introductory section of the questionnaire, assurance of confidentiality was missing. In section I, the word "intimate" was considered redundant. However, until further validation work is developed, the research team decided to maintain the term between brackets. In section III, there were two changes proposed and adopted (added between brackets for clarification):

Question 7: originally worded as 'This month were you satisfied after sexual activity?' adapted to 'This month were you satisfied after sexual activity (quality)?' as requested by three women (42.9\%).

Question 10: originally worded as 'This month were you satisfied with the frequency of sexual activity?' adapted to "This month were you satisfied with the frequency of sexual activity (quantity)" as requested by four women (57.1\%). Some general comments made are worth mentioning, as they may depend on the cultural context:

- 'If it were a man asking these questions, I believe I wouldn't feel comfortable... but I would have no problem in answering in the paper format (self-administered)'. (Participant three, 49 years, primary education, housewife).

- 'It is essential to be briefed on the purpose of such questionnaire'. (Participant two, 36 years, university degree, economist)

Table 1 - Demographic, medical and treatment characteristics of the sample $(n=134)$

\begin{tabular}{|c|c|}
\hline Variable & \\
\hline Age at the moment of diagnosis $(n=134)$ & Values \\
\hline Mean (standard deviation) & $42.8(5.7)$ \\
\hline Median; mode & $44.5 ; 45$ \\
\hline Minimum; maximum & $24 ; 50$ \\
\hline \multicolumn{2}{|l|}{ Age at the time of study $(n=134)$} \\
\hline Mean (standard deviation) & $47.3(6.1)$ \\
\hline Median; mode & $48.5 ; 52$ \\
\hline Minimum; maximum & $31 ; 57$ \\
\hline Educational level $(n=131)$ & $\mathrm{n} ; \%$ \\
\hline First cycle basic education (4 years) & $29 ; 22.1$ \\
\hline Second cycle basic education (6 years) & $7 ; 5.3$ \\
\hline Third cycle basic education (9 years) & $27 ; 20.6$ \\
\hline Secondary education (12 years) & $25 ; 19.1$ \\
\hline University degree & $39 ; 29.8$ \\
\hline Post-graduate studies & $4 ; 3.1$ \\
\hline Menopausal status $(n=131)$ & $\mathrm{n} ; \%$ \\
\hline Premenopausal & $25 ; 19.1$ \\
\hline Perimenopausal & $24 ; 18.3$ \\
\hline Postmenopausal & $82 ; 62.6$ \\
\hline Morphology $(n=134)$ & $\mathrm{n} ; \%$ \\
\hline All others & $16 ; 11.9$ \\
\hline Invasive ductal carcinoma & $118 ; 88.1$ \\
\hline Treatment $(n=134)$ & $\mathrm{n} ; \%$ \\
\hline Chemotherapy (yes) & $107 ; 79.9$ \\
\hline Radiotherapy (yes) & $100 ; 74.6$ \\
\hline Hormonotherapy (yes) & $83 ; 61.9$ \\
\hline Surgery (yes) & $134 ; 100.0$ \\
\hline Type of Surgery $(n=134)$ & $\mathrm{n} ; \%$ \\
\hline Radical mastectomy (yes) & $55 ; 41.0$ \\
\hline Conservative surgery (yes) & $79 ; 59.0$ \\
\hline
\end{tabular}

Note: Women may have been submitted to more than one surgical procedures 


\section{Other forms of validity and reliability}

A sample of 134 women was constituted, with a mean age of 42.8 years, the majority having past menopause ( $n=82 ; 62.6 \%$ ), and having been subject to breast cancer surgery $(n=134 ; 100.0 \%)$. Detailed characterization of the study recruits is presented in Table 1. Despite the menopausal status, no women were taking hormone replacement therapy.

As various samples have been used, Fig. 1 illustrates women comprising each of these samples.

\section{Construct validity}

PCA indicated the existence of three factors in the Portuguese version of the SAQ, as in its original version. ${ }^{34}$ These three factor structure explained $75.5 \%$ of the variance, approximately $10 \%$ more than the original. Additionally, in the modified version, more than half the variance is explained by the pleasure domain (Table 2). The distribution of items composing the three domains was quite similar to the originally presented in the English version, but with differences worth discussing.

\section{The sexually inactive group}

There were 32 women classifying themselves as sexually inactive $(23.9 \%)$. The main reasons for sexual inactivity were lack of interest or motivation $(n=18 ; 56.3 \%)$, not having a partner $(n=17 ; 53.1 \%)$, psychological (e.g. not feeling well with body image) and physical problems ( $\mathrm{n}$ $=6 ; 18.8 \%$ each), being too tired $(n=4 ; 12.5 \%)$ and partner problems (i.e., partner not interested, partner's rejection or partner's physical problem) $(n=3 ; 9.4 \%)$.

\section{Discriminant validity}

Different subgroups were constituted to test discriminant validity. ${ }^{34}$ Among respondents classifying themselves as being sexually active $(n=102), 96$ delivered valid, complete SAQ-III scores. The pleasure domain mean score was 9.96 $(S D=4.13 ;$ median $=11.0)$, for the habit domain was 4.55 $(S D=2.09 ;$ median $=4.0)$ and for the discomfort domain was $2.96(\mathrm{SD}=2.08$; median $=3.0)$.

Only women having complete information for SAQIII ( $n=96$ ) and for the co-variable under analysis were considered. Therefore, the number included in each subanalysis may vary. There were no significant differences between age groups for any of the three domains. However, women having been through chemotherapy exhibited higher levels of habit ( $p$-value $=0.022)$. Moreover, postmenopausal women showed significantly higher levels of discomfort ( $p$-value $=0.015$ ) and lower levels of habit and pleasure, although the latter not significant ( $p$-value $>0.05$ ).

PCA results were plotted for the three domains retained and FACIT-F, FACIT-An, Anxiety and Depression were plotted as supplementary variables (variables not included in the PCA calculations, but with their coordinates transformed accordingly, to illustrate how they fit in PCA results). Assuming the first two dimensions, Fig. $2 A$ indicates that the scoring for the pleasure dimension (dimension one) is positively correlated with quality of life and negatively correlated with anxiety and depression, indicating women with higher scores of pleasure tend to have higher scores in FACIT-F and FACIT-An scales and lower scores in Anxiety and Depression scales. Moreover, eight of the items composing SAQ are well correlated, suggesting pleasure

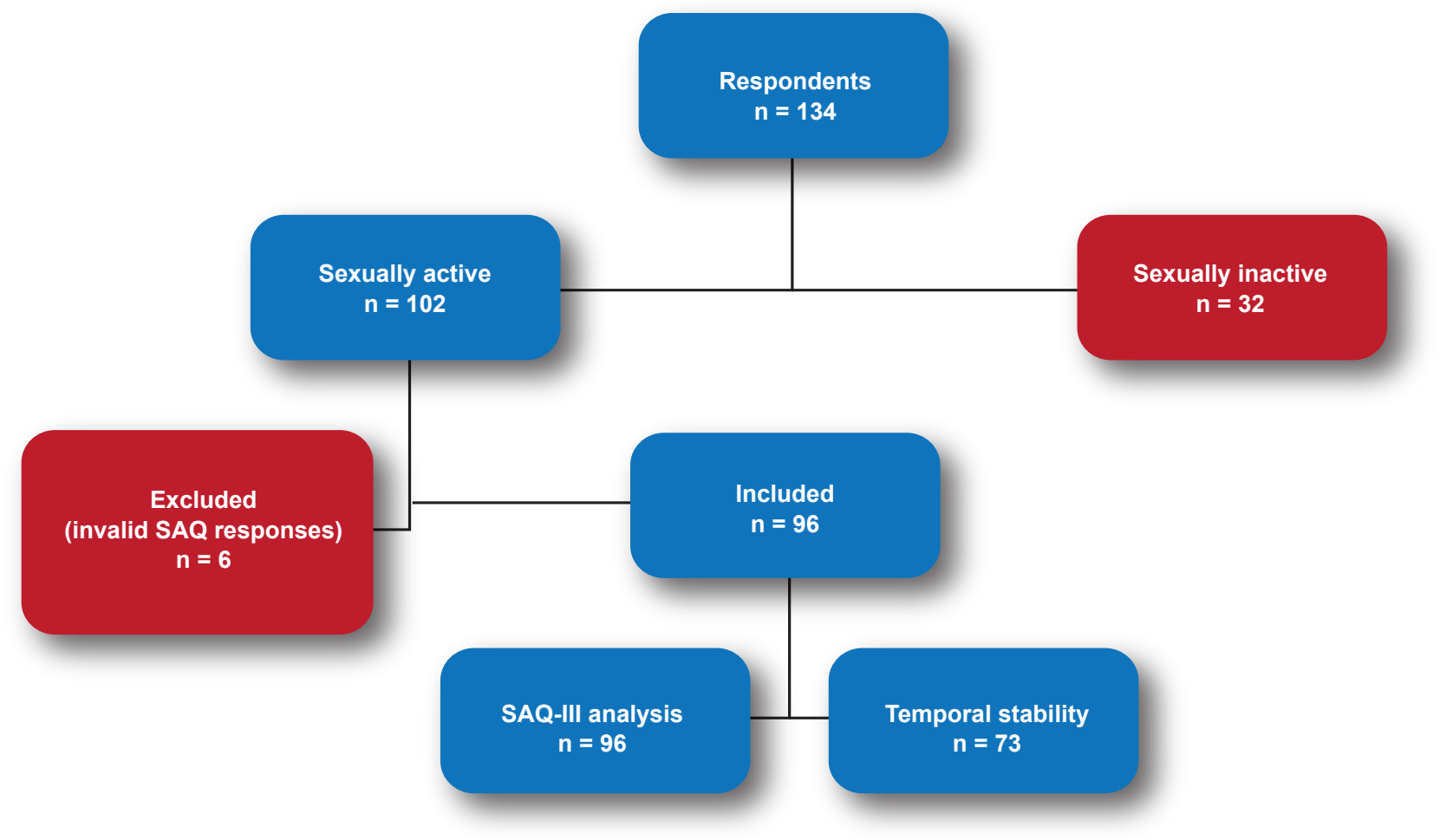

Figure 1 - Flowchart of sample recruits and subsamples analyzed 
Table 2 - Principal Components Analysis (varimax rotation) including Internal Consistency of the SAQ $(n=96)$

\begin{tabular}{|c|c|c|c|c|c|}
\hline Item & $\begin{array}{l}\text { Weighed factor } \\
\text { Loadings }\end{array}$ & Factor & $\begin{array}{c}\% \text { of } \\
\text { variance } \\
\text { explained }\end{array}$ & $\begin{array}{l}\text { Scale } \\
\text { if item } \\
\text { deleted }\end{array}$ & $\begin{array}{c}\text { Inter-item } \\
\text { correlation } \\
\text { (Standardised } \\
\text { Chronbach's alpha) }\end{array}$ \\
\hline $\begin{array}{l}\text { Was 'having sex' an important part of your life this } \\
\text { month? (q. one) }\end{array}$ & 0.804 & \multirow{5}{*}{ Pleasure } & \multirow{5}{*}{$53.1 \%$} & 0.564 & \multirow{5}{*}{0.732} \\
\hline Did you enjoy sexual activity this month? (q. two) & 0.858 & & & 0.526 & \\
\hline $\begin{array}{l}\text { In general, were you too tired to have sex? } \\
\text { (q. three) }\end{array}$ & 0.630 & & & 0.938 & \\
\hline $\begin{array}{l}\text { Did you desire to have sex with your partner(s) } \\
\text { this month? (q. four) }\end{array}$ & 0.789 & & & 0.586 & \\
\hline $\begin{array}{l}\text { In general, did you feel satisfied after sexual } \\
\text { activity this month? (q. seven) }\end{array}$ & 0.824 & & & 0.552 & \\
\hline $\begin{array}{l}\text { During sexual relations, how frequently did you } \\
\text { notice dryness of your vagina this month? (q. five) }\end{array}$ & 0.892 & \multirow[b]{2}{*}{ Discomfort } & \multirow[b]{2}{*}{$11.6 \%$} & NA & \multirow[b]{2}{*}{0.839} \\
\hline $\begin{array}{l}\text { Did you feel pain or discomfort during penetration } \\
\text { this month? (q. six) }\end{array}$ & 0.863 & & & NA & \\
\hline $\begin{array}{l}\text { How often did you engage in sexual activity this } \\
\text { month? (q. eight) }\end{array}$ & 0.555 & \multirow{3}{*}{ Habit } & \multirow{3}{*}{$10.8 \%$} & 0.658 & \multirow{3}{*}{0.739} \\
\hline $\begin{array}{l}\text { How did this frequency of sexual activity compare } \\
\text { with what is usual for you? (q. nine) }\end{array}$ & 0.598 & & & 0.729 & \\
\hline $\begin{array}{l}\text { Were you satisfied with the frequency of sexual } \\
\text { activity this month? (q. ten) }\end{array}$ & 0.735 & & & 0.523 & \\
\hline
\end{tabular}

NA: Not applicable

A

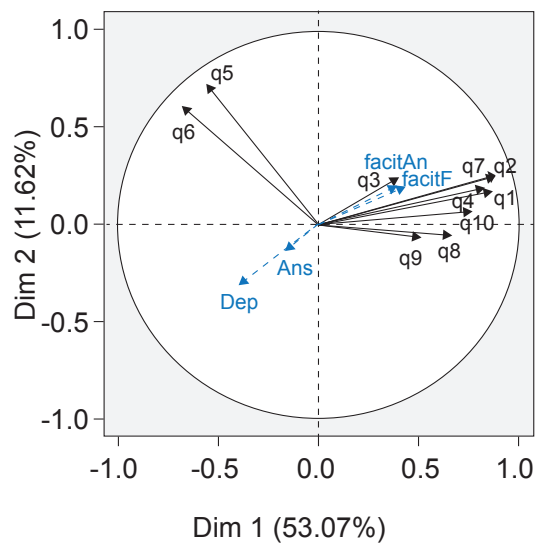

B

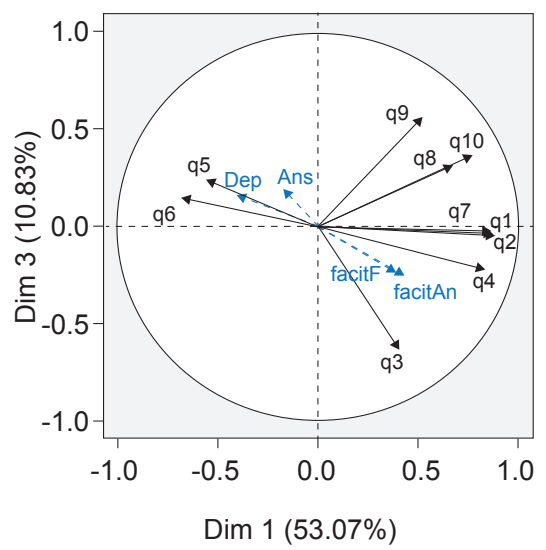

c

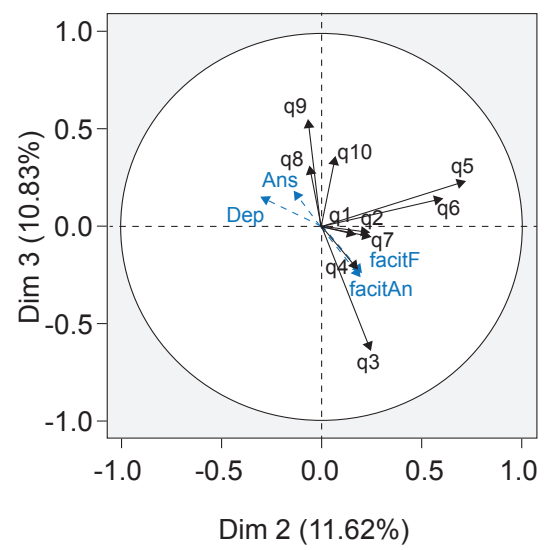

Figure 2 - PCA plots for components 1 - 2 (Pleasure-Discomfort), 2 - 3 (Discomfort-Habit) and 1 - 3 (Pleasure-Habit). Blue variables sign supplementary variables projected on PCA results $(n=96)$

and habit are related and that within the pleasure domain, question three is also correlated, although more distant (Fig.s 2A and 2B). Dimension two (discomfort) is formed by $S A Q$ items five and six, described as components of the discomfort domain, and do not show any correlation with supplementary variables. In dimension three (habit, Fig.s $2 \mathrm{~B}$ or $2 \mathrm{C}$ ), questions eight, nine and 10 cluster themselves, forming a clear construct, where item nine projects itself in the opposite direction to item three and fatigue-related QoL (Fig. 2C).

\section{Concurrent validity}

The FACT-An includes two questions exploring aspects of sexual activity. The item BL4 referring to interest in sex was compared to the SAQ's item 'Did you desire to have sex with your partner(s) this month?' indicating moderate 
Table 3 - Temporal stability of the SAQ $(n=73)$

\begin{tabular}{|c|c|c|c|c|}
\hline Item & Pearson's $r$ & Spearman's rho & Cohen's kappa & $p$-value \\
\hline Was 'having sex' an important part of your life this month? (q. one) & 0.875 & 0.854 & 0.633 & $<0.001$ \\
\hline Did you enjoy sexual activity this month? (q. two) & 0.828 & 0.819 & 0.623 & $<0.001$ \\
\hline In general, were you too tired to have sex? (q. three) & 0.557 & 0.538 & 0.444 & $<0.001$ \\
\hline Did you desire to have sex with your partner(s) this month? (q. four) & 0.808 & 0.777 & 0.550 & $<0.001$ \\
\hline $\begin{array}{l}\text { During sexual relations, how frequently did you notice dryness of } \\
\text { your vagina this month? (q. five) }\end{array}$ & 0.799 & 0.799 & 0.669 & $<0.001$ \\
\hline $\begin{array}{l}\text { Did you feel pain or discomfort during penetration this month? } \\
\text { (q. six) }\end{array}$ & 0.899 & 0.904 & 0.713 & $<0.001$ \\
\hline $\begin{array}{l}\text { In general, did you feel satisfied after sexual activity this month? } \\
\text { (q. seven) }\end{array}$ & 0.819 & 0.825 & 0.558 & $<0.001$ \\
\hline How often did you engage in sexual activity this month? (q. eight) & 0.775 & 0.774 & 0.611 & $<0.001$ \\
\hline $\begin{array}{l}\text { How did this frequency of sexual activity compare with what is usual } \\
\text { for you? (q. nine) }\end{array}$ & 0.637 & 0.671 & 0.592 & $<0.001$ \\
\hline $\begin{array}{l}\text { Were you satisfied with the frequency of sexual activity this month? } \\
\text { (q. ten) }\end{array}$ & 0.797 & 0.768 & 0.590 & $<0.001$ \\
\hline
\end{tabular}

agreement (and GS7 referring to satisfaction with sex life), which were used to judge concurrent validity of the SAQ (Pearson's $r=0.622$; Spearman's rho $=0.645$; $p$-value $<$ $0.001)$. The item GS7 referring to satisfaction with sex life was compared with SAQ's item 'In general, did you feel satisfied after sexual activity this month?' exhibiting even better results (Pearson's $r=0.770$; Spearman's $r h o=0.759$; $p$-value $<0.001)$.

The item in the BCPT judging pain during sexual activity was compared with SAQ's 'Did you feel pain or discomfort during penetration this month?' resulting in strong agreement (Pearson's $r=0.793$; Spearman's $r h o=0.802$; $p$-value < 0.001). The item in the BCPT focusing on vaginal dryness was compared with SAQ's 'During sexual relations, how frequently did you notice dryness of your vagina this month?' showing strong agreement (Pearson's $r=0.815$; Spearman's rho $=0.827 ; p$-value $<0.001$ ).

Results indicate that concurrent validity of the SAQ is high considering the external measures chosen.

\section{Temporal stability}

Data from 73 sexually active women responding to SAQ in two moments indicates that the temporal stability of all items is quite good, where the worse performing item was question three (Table 3).

\section{DISCUSSION}

Breast cancer diagnosis and treatment can be disruptive to several aspects of QoL and as the survivor population increases, more sensitive tools to evaluate the impact of cancer on patients' lives from their perspective are needed to enhance the quality of care provided. This study included information from an important patient sample and was the first to be developed in the Portuguese population with such characteristics. Additionally, the main outcome of the study was a patient-reported measure, highlighting the current shift in care provision witnessed worldwide. The validation results of the SAQ indicate this tool is acceptable to participants, despite its intimate nature. The adaptation of the $S A Q$ for Portugal resulted in a three factor structure as originally described. We tested a one and two factor solution, as described by Vistad and colleagues, and concluded the three factor solution was better as it described $75 \%$ of the variance, instead of $53 \%$ or $65 \%$, respectively. ${ }^{31}$ However, in our factor solution, all 10 SAQ items loaded into the three domains, differently to what was expected. The discomfort domain was the same in both versions. There were two additional items loading into the habit domain in our sample (item eight and 10), transforming this domain into a more robust construct including three items and with high internal consistency. Consequently, the pleasure domain comprised five items, instead of the original six, including the fatigue item (question three), which was left out of the domain composition in its original. We believe considering all items may be a possible strength of our version. The option to include question three was confirmed statistically and graphically, leading us to think this was the best approach in our population. Nonetheless, one must bear in mind that the quality of the PCA projection was suboptimal, indicating results should be interpreted with caution. Regarding the frequency item, this option to include it in the habit domain was explained by the fact that Portugal as a Latin country may naturally be expected to attribute more value to frequency and to consider it an important aspect of sexual performance. Moreover, it should be noted that the initial version of the SAQ was developed predominantly with women without cancer and only validated in women having mainly gynaecological cancers. Therefore, it is to be expected that it performs differently in breast cancer women. Despite these differences, results indicate that 
the SAQ is valid and reliable for use in Portugal in breast cancer survivors, maintaining the original psychometric properties. ${ }^{34}$ Temporal stability results were estimated based on a sample larger than originally reported, and yielding good estimates in line with published data for the original version. ${ }^{34}$ Nonetheless, additional validation in larger samples may help refine the adapted version. As mentioned, it is important to note that the validation of the adapted version for Portugal was only tested in breast cancer survivors. Therefore, results cannot be extrapolated to the general population or even to patients diagnosed with other cancer types. In the future, it could be interesting to additionally test it in gynaecological cancers. One of our main findings from using the SAQ was that the prevalence of sexual dysfunction among breast cancer survivors was $24 \%$, in line with the $29 \%$ reported in France using the same tool in a sample with similar characteristics ${ }^{38}$ Considering the existing evidence on the benefit of psychosocial interventions in improving outcomes of common sequelae of breast cancer, including sexual health, ${ }^{39}$ and as a result of the increased awareness of medical doctors about sexual dysfunction following this study, a specific medical appointment was developed to deal with aspects arising from cancer that impact on this important domain of a woman's life. In future research, participants will be contacted to evaluate how sexual dysfunction evolved over the past five years.

\section{REFERENCES}

1. Stewart BW, Wild CP. World Cancer Report 2014. Lyon: International Agency for Research on Cancer;2014.

2. George F. Causes of deaths in Portugal and challenges in prevention. Acta Med Port. 2012;25: 61-3.

3. Bastos J, Barros H, Lunet N. Evolução da mortalidade por cancro da mama em Portugal (1955-2002). Acta Med Port. 2007;20:139-44.

4. Amaro J, Severo M, Vilela S, Fonseca S, Fontes F, La Vecchia C, et al. Patterns of breast cancer mortality trends in Europe. Breast. 2013;22:244-53.

5. De Angelis R, Sant M, Coleman MP, Francisci S, Baili P, Pierannunzio D, et al. Cancer survival in Europe 1999-2007 by country and age: results of EUROCARE--5-a population-based study. Lancet Oncol. 2014;15:2334.

6. Mols F, Vingerhoets Ad JJM, Coebergh JW, van de Poll-Franse LV. Quality of life among long-term breast cancer survivors: a systematic review. Eur J Cancer. 2005;41:2613-9.

7. Baker F, Denniston M, Smith T, West MM. Adult cancer survivors: how are they faring? Cancer. 2005;104: 2565-76.

8. Panjari M, Bell RJ, Davis SR. Sexual function after breast cancer. J Sex Med. 2011;8:294-302.

9. World Health Organization. ICD-10: International Statistical Classification of Diseases and Related Health Problems. Geneva: WHO; 1992.

10. Sarrel PM. Effects of hormone replacement therapy on sexual psychophysiology and behavior in postmenopause. J Womens Health Gend Based Med. 2000;9:S25-32.

11. Nappi RE, Albani F, Valentino V, Polatti F, Chiovato L, Genazzani AR. Aging and sexuality in women. Minerva Ginecol. 2007;59: 287-98.

12. Files JA, Allen SV, Pruthi S. Hormone therapy for management of menopausal symptoms: understanding [corrected] breast cancer risk. Minerva Ginecol. 2012;64: 223-30.

13. Fallowfield L, Cella D, Cuzick J, Francis S, Locker G, Howell A. Quality of life of postmenopausal women in the Arimidex, Tamoxifen, Alone or in Combination (ATAC) Adjuvant Breast Cancer Trial. J Clin Oncol. 2004;22:4261-71.

14. Graziottin A. Breast cancer and its effect on women's body image and

\section{CONCLUSION}

The adapted SAQ is a valid tool for assessing sexual activity in Portuguese breast cancer survivors. The results of this study were used to modify the structure of care previously provided, leading to a more comprehensive approach. Additional validation in the overall population and in samples with different characteristics is needed.

\section{PROTECTION OF HUMANS AND ANIMALS}

All procedures performed in studies involving human participants were in accordance with the ethical standards of the institutional research committee (Ethics Committee of the do IPOLFG-CROL, SA) and with the 1964 Helsinki declaration and its later amendments or comparable ethical standards. Written informed consent was obtained from all individual participants included in the study.

\section{DATA CONFIDENTIALITY}

The authors declare having followed the protocols in use at their working center regarding patients' data publication.

\section{CONFLICTS OF INTEREST}

All authors declare there are no conflicts of interests direct or indirectly linked to the research.

\section{FUNDING SOURCES}

This study was totally funded by Merck Foundation.

sexual function. In: Goldstein I, Meston C, Davis S, Traish A, editors Women's Sexual Function and Dysfunction. London: Taylor and Francis; 2006. p. 276-81.

15. Engel J, Kerr J, Schlesinger-Raab A, Sauer H, Holzel D. Quality of life following breast-conserving therapy or mastectomy: result of a 5 year prospective study. Breast J. 2004;10: 223-31.

16. Thors CL, Broeckel JA, Jacobsen PB. Sexual functioning in breast cancer survivors. Cancer Control. 2001;8: 442.

17. Lewis RW, Fugl-Meyer KS, Corona G, Hayes RD, Laumann EO, Moreira ED, et al. Definitions/epidemiology/risk factors for sexual dysfunction. 9J Sex Med. 2010;7:1598-607

18. Dimitropoulos K, Bargiota A, Mouzas O, Melekos M, Tzortzis V, Koukoulis G. Sexual functioning and distress among premenopausal women with uncomplicated type 1 diabetes. J Sex Med. 2012;9:137481.

19. Pasquali D, Maiorino MI, Renzullo A, Bellastella G, Accardo G, Esposito $D$, et al. Female sexual dysfunction in women with thyroid disorders. J Endocrinol Invest. 2013;36:729-33.

20. Raggio GA, Butryn ML, Arigo D, Mikorski R, Palmer SC. Prevalence and correlates of sexual morbidity in long-term breast cancer survivors. Psychol Health. 2014;29:632-50.

21. Kornblith AB, Herndon JE, Weiss RB, Zhang C, Zucherman EL, Rosenberg $S$, et al. Long-term adjustment of survivors of early-stage breast carcinoma, 20 years after adjuvant chemotherapy. Cancer. 2003;98:679-89.

22. Francis PA, Regan MM, Fleming GF, Láng I, Ciruelos E, Bellet M, et al. Adjuvant ovarian suppression in premenopausal breast cancer. $\mathrm{N} \mathrm{Engl}$ J Med. 2015;372:436-46.

23. Gray RG, Rea R, Handley K, Bowden SJ, Perry P, Earl HM, et al. aTTom: Long-term effects of continuing adjuvant tamoxifen to 10 years versus stopping at 5 years in 6,953 women with early breast cancer. J Clin Oncol. 2013,31: abstr 5.

24. Davies C, Pan H, Godwin J, Gray R, Arriagada R, Raibna V, et al. Long-term effects of continuing adjuvant tamoxifen to 10 years versus stopping at 5 years after diagnosis of oestrogen receptor-positive breast 
cancer: ATLAS, a randomised trial. Lancet. 2013;381:805-16.

25. Elnashar AM, El-Dien MI, El-Desoky MM, Ali OM, El-Sayd MH. Female sexual dysfunction in Lower Egypt. BJOG. 2007;114:201-6.

26. Nobre PJ, Pinto-Gouveia J, Gomes FA. Prevalence and comorbidity of sexual dysfunctions in a Portuguese clinical sample. J Marital Ther. 2006;32:173-82.

27. Pacagnella RC, Vieira EM, Rodrigues Jr OM, Souza C. Adaptação transcultural do Female Sexual Function Index. Cad Saude Publica. 2008;24:416-26.

28. Hentschel H, Alberton DL, Capp E, Goldim JR, Passos EP. Validação do Female Sexual Function Index (FSFI) para uso em língua Portuguesa. Rev HCPA. 2007;27:10-4.

29. Dennerstein $L$, Lehert $P$. Women's sexual functioning, lifestyle, mid-age, and menopause in 12 European countries. Menopause. 2004;11:77885.

30. Atkins L, Fallowfield LJ. Fallowfield's Sexual Activity Questionnaire in women with without and at risk of cancer. Menopause Int. 2007;13:1039.

31. Vistad I, Fossa SD, Kristensen GB, Mykletun A, Dahl AA. The sexual activity questionnaire: psychometric properties and normative data in a Norwegian population sample. J Womens Health. 2007;16:139-48.
32. Guillemin F, Bombardier C, Beaton D. Cross-cultural adaptation of health-related quality of life measures: literature review and proposed guidelines. J Clin Epidemiol. 1993,46:1417-32.

33. Bowling A. Research methods in health, investigating health and health services. Berkshire: Open University Press; 2002.

34. Thirlaway K, Fallowfield L, Cuzick J. The sexual activity questionnaire: A measure of women's sexual function. Qual Life Res. 1996;5:81-90.

35. Zigmond AS, Snaith RP. The Hospital Anxiety and Depression Scale. Acta Psychiatr Scand. 1983;67:361-70.

36. Cella D. The Functional Assessment of Cancer Therapy-Anemia (FACTAn) Scale: a new tool for the assessment of outcomes in cancer anemia and fatigue. Semin Hematol. 1997;34:13-9.

37. R Core Team., A Language and Environment for Statistical Computing. RFoundation for Statistical Computing, Vienna, Austria. 2014. [consulted 2014 ago 10]. Available from: http://www.Rproject.org/.

38. Brédart A, Dolbeault S, Savignoni A, Besancenet C, Giami A, Michaels $S$, et al. Prevalence and associated factors of sexual problems after early-stage breast cancer treatment: results of a French exploratory survey. Psychooncology. 2011;20:841-50.

39. Alfano CM, Rowland JH. Recovery issues in cancer survivorship: a new challenge for supportive care. Cancer J. 2006;12:432-43. 